\title{
An examination of citizen involvement in crime prevention
}

\author{
Ho-Youn Kim
}

Dept. of Security Management, Kyonggi University, Suwon, South Korea

Email address:

security737@gmail.com

\section{To cite this article:}

Ho-Yeon Kim. An Examination of Citizen Involvement in Crime Prevention. Social Sciences. Vol. 2, No. 5, 2013, pp. $161-167$.

doi: $10.11648 /$ j.ss.20130205.11

\begin{abstract}
Research has consistently showed that government has been held in low regard and the loss of confidence in government is mainly due to low productivity and inefficiency of government. The police are also confronted with low productivity. Citizens have more demands, but police have fewer resources. Increasing productivity is considered as an important task for government. Many politicians adopted "reinventing the government" as their slogan, and the coproduction effort has been recognized and promoted as "the law enforcement manifestation of reinventing movement". This movement is apparently gaining tremendous support not only from law enforcement agencies but also from the general public. However, it has not been completely assured that collective citizen involvement in crime prevention is a sound and effective way to control crime, and thus reduce fear of crime. This research examines the effectiveness and problems associated with the coproduction effort such as Neighborhood Watch Program and Citizen Patrol.
\end{abstract}

Keywords: Co-production, Crime Prevention, Neighborhood Watch, Citizen Patrol

\section{Introduction}

For decades surveys have indicated that government has been held in low regard. A survey of college honor society members [1] showed that only six percent of the sample said that government work was "challenging and intellectually stimulating," and less than one in nine entered American government at any level. Government seems to have lost public confidence. However, many people are still joining government, and other major institutions, even universities, also have lost public confidence. There is something more than simple.

In any case, many people think that the loss of confidence in government is mainly due to low productivity and inefficiency of government. The police are also confronted with low productivity. Citizens have more demands, but police have fewer resources [2].

Increasing productivity is considered as an important task for government. Many politicians adopted "reinventing the government" as their slogan. These slogans called for a market-oriented, customer-driven government, which emphasizes empowerment, decentralization and a focus on preventing rather than on curing. These new initiatives are delivered by public organizations employing participative, team-oriented management systems [3]. Even though the coproduction effort shares the same characteristics with this movement, such concepts as team-policing or problem-oriented policing predate the formal reinventing government movement. In any case, the co-production effort has been recognized and promoted as "the law enforcement manifestation of reinventing movement" [3].

This movement is apparently gaining tremendous support not only from law enforcement agencies but also from the general public. We are entering the heyday of community crime prevention. Never before has citizen involvement in crime prevention received such an extensive support from various parts of society, which include the media, law enforcement agencies, the academic society, and the general public. Many researchers have put an emphasis on the benefits of citizens' participating in the production of municipal services. However, some studies show that police-citizen coproduction does not contribute to increased production efficiency [4]. In addition, there are also negative aspects to coproduction such as possible corruption because of intimate relationship between the police and citizen, which few studies have dealt with.

While coproduction spreads widely at a rapid rate, it has not been completely assured that collective citizen involvement in crime prevention is a sound and effective way to control crime, and thus reduce fear of crime. This research will examine the effectiveness of the coproduction effort (Neighborhood Watch Program and Citizen Patrol). In addition, this report will also examine the equity issues related to the coproduction efforts. As not all citizens can 
equally participate in coproduction, they may not receive equal benefit from co-production, which raises issues of equity. Citizens may have unequal chance or access to coproduction activities according to their income, race, or age.

\section{Defining Coproduction}

While most of the definitions of coproduction focus on the contribution of citizens to the production of public services, they vary greatly in important criteria. In this study, the definition of coproduction by Robert Warren will be used; "coproduction" is "the interactions between individuals or groups and public agencies that augment or contribute to the production of urban services" [5].

This definition distinguishes conjoint interaction from other production-side input by citizens. The concept of coproduction in this study is limited to the activities that involve conjoint behavior between citizens and police agencies, such as Neighborhood Watch (block watch) and Citizen Patrol. The "ancillary production" involving actions upon which the operation of government is dependent and thus necessary for government to function as a service provider, such as parents teaching their children to obey laws and people serving on juries is excluded. And "parallel production" which refers to the actions that are undertaken without direct or indirect interaction with government, such as a family installing a dead-bolt lock, buying a gun, or elderly persons staying home at night, are also excluded [5] The purpose of excluding these production-side input actions without conjoint behavior is to clarify the operational meanings of co-production.

\section{Types of Citizen Response to Crime}

Bowaird [6] pointed out that citizens view private protection in and around the home as a high priority, and most citizens adopt private measures more often than collective ones. He suggested that this private security measures can generally be dichotomized into avoidance and protective measures. Protective measures include activities that employ a variety of devices or equipment for protection. Defensive measures include purchasing and keeping a gun or a dog; altering the physical setting of the home by installing security alarms, fences, doors and window locks, or outdoor lighting; manipulating appearances by leaving on lights, televisions, or radios when away from home [7].

Avoidance measures themselves can be classified as spatial (e.g., avoiding certain places in the city), temporal (e.g., avoiding going out at night), or situational (e.g., refusing to answer the door). These efforts have contributed to a considerable growth of private security industry; private protection expenditures now exceed public expenditures [7].

In addition to private-level response, citizens also adopt collective-level response. Unlike private-level response, collective-level response assumes benefits to all individuals in a community whether they participate in that activity or not. One of the most common collective responses is the Neighborhood Watch program. People watch neighbors' homes and look out for suspicious activities in the neighborhoods. Some more active people organize patrols to provide the same protection as the police patrols do, even if it cannot totally be the same.

\subsection{Neighborhood Watch}

The neighborhood or block watch program is another form of citizen crime prevention activity. It is an attempt to improve citizen reporting of crimes or suspicious events and people in the neighborhood. Residents in a neighborhood are urged to be sensitive to any criminal activity and call the police when they detect such activity. Neighborhood Watch programs are consistent with informal social control theory mentioned above. And, it is also believed that increased watchful eyes will discourage potential criminals from committing a crime, which is often referred to as an 'opportunity reduction'.

National Neighborhood Watch Program in the U.S., established under a grant to the National Sheriffs' Association from the Law Enforcement Assistance Administration in 1972, has been trying to widely disseminate the information about neighborhood watch activities. Consequently, there are thousands of neighborhood watch programs throughout the United States It is estimated that one out of every five families in the United States lives in a community with a watch-type program [8]. The Neighborhood Watch program received strong public support in opinion polls in 1982 and national policy has specifically encouraged this type of program throughout the Community Anti-crime Program and the Urban Crime Prevention Program [9]. Neighborhood Watch involves citizens who act as "ears and eyes" of police in a community. Although the structure and functions may differ from one another, there are basically three aspects of this program: sharing information about the crime problems of the community, reporting of any suspicious activity to the police, and making plans for engaging in surveillance. The initiation of this program should be made by a police officer or a private organizer [8].

Even though Neighborhood Watch gained substantial support from various parts of America, and has been recommended as a feasible and attractive solution to crime-related neighborhood conditions, and the informal social control theory tells that Neighborhood Watch is conducive to the security of a community, there is "little systematic and precise evidence to date" about the effectiveness of Neighborhood Watch [10]. It is very difficult to measure the impact of co-production on crime and fear in an empirical setting, as is normal in other social studies. Dependent variables other than co-production program are hard to completely exclude, and errors may be 
committed during the study. Seattle and Chicago evaluation experiences would be good examples of this kind of difficulty. In both cases, mixed results have been reported, with respect to the effectiveness of Neighborhood Watch program. The Seattle evaluation presented generally positive results of reduction in residential burglary in the target area. On the contrary, the Chicago evaluation yielded generally negative results of increase in various social problems including fear of crime. The three Chicago neighborhoods within which the program was implemented showed significant increases in a number of problem areas, including perception of the crime problem, fear of crime, and concern about the future of the neighborhood. Thus, the program made almost no effect on the community [9].

Regardless of activity, law enforcement agencies normally tend to count their success in terms of quantity, rather than quality. And, Rosenbaum contends from his personal experience that police officers' effort to plan block meeting and maintain them beyond the first meeting is quite unusual. National assessment of Neighborhood Watch indicated that watch programs are not as "systematic" or "coordinated" as the popular definition suggests [9]

The Neighborhood Watch program appears to lack tangible result in reducing crime and fear. Then how about psychological effects? Do research findings support informal social control theory? Do watch programs produce the types of behavior that social control theory expect and eventually reduce crime and fear? Research findings show only mixed results. Several studies have found that those who participate in watch programs are more likely to engage in various prevention behaviors, which may reduce their chances of victimization [11]. But, the Chicago study revealed the opposite result. They found that "neighborhoods that had watch programs generally did not differ from those which did not in terms of residents' level of social interaction on the street, neighborhood surveillance (i.e., watching others' homes while away), home protection behaviors, self-protection behaviors, or intervention behaviors" [12]. Watch programs failed to affect residents' behavior in any measureable way.

Judging from these findings, the Neighborhood Watch organization does not necessarily alter the members' behavior in a neighborhood. Even if it does, it is less likely to affect every resident in the neighborhood. Rather, it is more likely to impact a limited number of people who actively participate in the activity, which is contrary to the informal social control theory that such collective activity can change the pattern of informal social control in a neighborhood. However, changing behavior requires changing norms and values, and it does not happen when a few people get together and have a meeting once in a year. It would take a long time and substantial number of participants to produce expected results. Thus, effects of informal social control need more intense and longitudinal research [12]. The current level of participation in a few years seems not enough for a watch program to have informal social control effect.

\subsection{Citizen Patrols}

Citizen patrols, such as Guardian Angels, are organized by the residents of an area to patrol their neighborhood. Members of this club regularly walk and patrol the street, and when they happen to encounter a crime situation they call the police rather than directly dealing with it. The range of functions performed by these patrols varies considerably. Some patrol the neighborhood on foot, and others use vehicles, maintaining contact through citizen band radios. A 1977 National Evaluation Program report on citizen patrol projects estimated that more than 800 resident patrols are currently active in urban areas in the United States [13]. The number must have gone up during the last thirty years, given the fact that the coproduction effort has gained a lot of momentum. Large cities like New York, Los Angeles and California have several thousand block clubs; cities like Compton and Oakland, Minneapolis, Minnesota, and Philadelphia, Pennsylvania have from thirty to several hundred clubs [9].

Citizen patrol and Neighborhood Watch programs are usually organized on a block level, which is consistent with the finding that the smaller the community, the better the social control. The block club normally provides a good starting point for an organized response to crime. The block is the level at which citizens can easily watch what is going on and recognize suspicious activity in the neighborhood. The block is also the level at which citizens can have more frequent and intimate contact with each other, which makes it easier to build informal control over the neighborhood. It simplifies the organizer's task because it is easier to bring together a limited number of people in a specific geographic area than in larger community level. The Citizens Involvement Network suggests that an organized block association can be a key factor in whether or not a block's crime prevention initiative will be a sustained effort [13]. The block level tends to get more interest from citizens because they are more likely to have vested interest at that level, such as their business, stores, and homes.

To organize a block club, police chief or community-relations head will have to initiate recruiting volunteers. He/she can encourage individual organizer for recruitment. Sometimes it would be better to use individuals, because such individuals have easy access to volunteers and it matches the civilian-oriented nature of a block club. Even if individual organizers initiate the recruitment, police assistance is indispensable. Cooperation between individual and police should always be maintained.

Not much study about the effectiveness of citizen patrols on fear and crime has been done. But the Baltimore experience shows a positive effect of citizen patrol on the crime rate. Baltimore launched a citizen patrol program and reported a seven percent drop in street crime in the first year. Washington launched an "orange hat patrol" program which seems to be making a difference, even if there is no specific data. Drunks and drug dealers avoid orange hat patrol area and thus making the streets a safer place to walk. Citizen 
patrollers are also involved in litter collection and gathering intelligence from shopkeepers and passers-by [14].

However, these results are not based on any systematic study, thus it is difficult to be accepted as scientific evidence for the effectiveness of citizen patrol. As mentioned above not much study has been done about citizen patrols systematically. But, instead, a study about a police patrol service is available, which provides indirect evidence about the effectiveness of patrol service. In the study of the effects of physical design features and social characteristics of housing development on crime, fear, and instability conducted by U. S. Justice department, researchers found that police service had no effect on resident's fear of crime and community burglary; police service showed virtually no total effects on burglary, fear, or instability. And even surprisingly, police service showed a negative effect on crime. The more frequently the police patrol, the higher is the rate of personal crime. More specifically, the effects of police patrol on burglary was -.01, on instability was .01 , on fear of crime was .05 , and on personal crime was .42 [15].

This result indicates that more frequent police patrol leads to a higher rate of personal crime. But we cannot completely support this finding, because it is vulnerable to counter interpretation. In other words, the causal relationship has not been clarified. Police are likely to patrol more frequently where the rate of personal crime is high. Then, the cause of relationship would be police patrol, rather than high personal crime. However, even if police patrol might not lead to higher personal crime, it appears to have failed to reduce the personal crime rate, because there is still a high rate of personal crime with increased patrol service. So, overall, police service showed virtually no effect on crime, instability, and fear. This result reflects the limits of preventive measures against crime. Criminals do not seem to care much about the police patrol which just passes by in a short time. Some of them might know when police patrol a specific area, and by avoiding that time they can commit crime without any fear of immediate arrest. When professional, 24 hour operating formal service does not have any positive effect on crime and fear, how can virtually untrained, informal, and irregular citizen service have a substantial effect on crime?

\section{How Collective Response Affects the Crime Rate}

It is believed that there is a relationship between informal social control and crime. In other words, informal social control is believed to be able to affect criminal behavior and prevent crime. Joseph Ryan, a 25-year New York City police veteran who teaches at Pace University in Manhattan, states that "although crime has gone down in the past few years, it is still higher than it was 30 years ago in most places. It may have to do with the weakening of community ties" [16].
Even though theoretical assumption about the relationship between informal control and crime seems plausible, not much study has been conducted on this subject, and there is little evidence to clarify the actual effect of informal social control on crime prevention. However, some empirical researches found positive relationship between informal group formation and neighborhood cohesion, and between neighborhood cohesion and social control [15].

The relationship between social cohesion and social control has been a major theme in sociology since the work of Durkheim, Toennies, and Weber in the late 19th century, and urban ethnographies in the 1930's.

Social control is a societal mechanism for maintaining social order, and making individuals to behave in expected or predictable manner. Social control can be divided into formal and informal social control. Formal control involves the enforcement of codified norms (laws) through a formal organization, such as the police, the military, or a corporation. Informal control is the enforcement of norms based on custom or common agreement [15].

Neighborhood organizations are the most formal form of informal control. Even if such organizations do not always exercise social control, they certainly are capable of doing so. They reinforce informal norms for desirable social behavior by bringing people together in activities which imply the indication of their standards of conduct. Such activities as neighborhood clean-up, neighborhood watch meeting, or graffiti removal send messages to members of a community about their informal norms and acceptable code of conduct.

Brannan et al. [7] argued that developing informal groups generally leads to the development of group cohesion, and "the greater a group's cohesiveness... the greater the force holding the group together, and the greater the force necessary to pull the group apart”. Ostrom [17] also contended that the greater the cohesiveness of a group, the greater control the group has over its members. Two major elements in group formation and the subsequent development of group cohesion are physical proximity of individuals and the frequency of contract or interaction. Frequent contact is believed to be an indication of similar interest, character, and belief [18].

Another critical factor is group size. Group size affects the degree of face-to-face contact and consequent cooperation. The larger the number of a group, the fewer the face-to-face interactions and cooperation. As a group gets bigger, it develops more formal rules and regulations, and group members begin to break apart. Ostrom [17] argued that the group dynamics literature clearly demonstrates that small groups are more cohesive than large groups. This finding suggests that social control is the most effective in small and intimate cohesive groups.

Leher [16] contended that neighborhoods where residents say they are likely to watch out for one another have crime rates about 40 percent lower than those in similarly situated areas without such community closeness. Schafer et al. [19] 
have shown that fear of crime is lower in neighborhoods where residents feel more responsibility and control over what happens in the area. The bulk of the literature shows that crime is most prevalent in poor, nonwhite, transient areas. These areas appear to lack cohesion to deter criminals from within and outside.

\section{Equity Issues}

One of the most important problems related to watch program is the equity issue. Before dwelling on the relationship between coproduction and the equity issue, the concept of equity needs to be understood.

Equity is an issue of distributive justice. It is about fairness. It calls for equal treatment for the equals and unequal treatment for the unequals [20]. But, what is fair and equal treatment? How can it be measured? Fairness may vary according to circumstances and social context. Different standards or criteria for fairness will result in different outcomes. Thus, we need to set criteria before dealing with the question of equity. William [20] provides five criteria for equity, especially for those who deal with issues having spatial dimensions.

Equality is the first criterion. In local government services, equality simply means equal service for everyone in the community. However, the usefulness of this criterion has certain limitations. First, it is inconsistent with the other four equity criteria. If citizens have unequal demands for example, it leads to unequal services. Second, equal distribution is often physically impossible. The inability to locate services equidistant from citizens leads to unequal benefits for citizens. Third, equality may differ according to criteria [20]. For example, input equality focuses on resources, expenditure, facilities, and etc. On the other hand, output equality focuses on product result. Lineberry [21] points out that "virtually all service-evaluation challenges have focused narrowly on 'input equality' rather than on the more significant issue of 'output equality"'. The downside of input equality is that it may have only a weak relationship to outputs. More police officers do not guarantee an increase in arrest rates. From the citizen's point of view, input is relatively unimportant as long as output is satisfactory in quality. Lineberry [21] contended that "the relentless pursuit of equality as a social or judicial policy entails tradeoffs with other important values". In addition, equality does not necessarily guarantee efficiency. If the goal of a police department is to minimize the crime rate in a community, they may produce better outcomes by concentrating their resources in higher crime area than distributing them equally overall.

Need is the second criterion. Those who need more should get more, and vice versa. The most important point is that unequals should be treated unequally. But, identifying needs in an empirical setting is not that easy. Lineberry [21] contended that "the concept of need is a slippery one that, like beauty, tends to exist in the eyes of the beholder". For example, we can say that a better educated area needs more libraries, because they read more. But, we can also say that a less educated area needs more libraries because they cannot afford private reading materials, and need education.

Demand is the third criterion. As the believers in market economy stressed, services are provided to meet demands. It is also related to the notion of political officers' accountability to the electorate in a democracy. This criterion involves the notion that those who have an active interest in a service should be rewarded. On the contrary, it is not equitable to provide services to reluctant citizens. By responding properly to demands, one may achieve a fair outcome. Demands are manifested either through the use of a service or by requests and complaints. Groups of people claim adjustment in services by means of demand, and the public officers are believed to agree to their requests if they are to be accountable to their citizens. However, all demands cannot be responded. Response to a demand may worsen the disparity, or it may be limited financially. Thus, one also needs to consider equality, need, or willingness to pay in choosing to whom to respond [20].

Preferences are the fourth criterion. Demands indicate preferences, but "not all preferences are expressed through use of a service or through requests or complaints of a service" [20]. Some people may not be intensely motivated or may not have proper access to a service. Many people may be left unaccounted for demands. There are several ways to overcome this problem, such as public hearing, stratifying government committees, or surveys. However, each of them has certain limitations in achieving a representative sample of demands [20].

Willingness to pay is the last criterion. This criterion simply means that those who use a service should pay, while nonusers should not. Willingness to pay is easy to apply when beneficiaries are few and services are not essential. But it is not easily applied, and should not be applied to many collective goods, like police, park, and fire services. These services are traditionally free responses to requests for services. These criteria of equity do not stand alone. They are interrelated with one another. More than one criterion is drawn on in thinking about a problem [20].

Citizen coproduction may also have negative impact on equity in service delivery. Since coproduction requires time and money, and they are not equally distributed across the community, "coproduction may actually increase differentials in safety and security across neighborhoods" [10]. As was indicated above, coproduction is common among affluent individuals who have their investment and property to protect and have time and other resources to invest in such activity. Even though some researchers, like Rohe and Greenberg [22], argue that "group anti-crime efforts are more likely to occur in more densely populated, lower income areas, with a relatively greater proportion of non-white residents", many surveys found that higher-income individuals are more likely to participate in Neighborhood Watch program than lower-income individuals [5]. In other words, more affluent residents have 
a greater willingness to participate and pay for Neighborhood Watch than poorer ones. Poorer residents are not only more likely to lack resources to invest in fighting crime, but also more likely to have higher crime rate.

The bulk of the literature shows that crime is most prevalent in poor, nonwhite, transient areas. These areas appear to lack the cohesion to deter criminals from within and outside. Many studies show that crime rates tend to be the highest in low income, predominantly black neighborhoods near the city core [23]. These neighborhoods tend to have low rates of home ownership, thus discouraging the building of cohesion.

Studies found that crime is also lower in residentially stable than unstable neighborhoods (National Institute of justice, 1982). Suttles [24] reports in his study of a poor Chicago neighborhood that stable Italian, Mexican, and Puerto Rican communities were able to form extensive communication networks and had fewer burglaries and robberies than surrounding areas. Blacks, on the contrary, lived in transient neighborhood and had a higher crime rate. The usual explanation is that long-term residence enabled neighbors to develop intimate informal interaction with others and consequently strong emotional ties to the neighborhood [23]. These findings suggest the dilemmas poor neighborhoods are facing: they have higher crime rate, yet have fewer private and collective protection measure.

Even though there is no empirical evidence about the displacement effect of Neighborhood Watch, it is possible that if only more affluent neighborhoods have Neighborhood Watch programs, and if their efforts are successful, it may result in displacement of crime. Criminals may want to avoid risk of being arrested in a highly patrolled or watched area and move to less protected areas. This also may increase inequity. Thus, if a city provides equal police service across the community, fostering Neighborhood Watch program may result in inequity. However, many jurisdictions are faced with fiscal constraints and increasingly rely on ways to transfer production costs to citizens. The possibility of inequity increases with increasing reliance with such strategy [5]. Therefore, it may be necessary to reallocate police services to neighborhoods that cannot participate in such activity so that equity in safety can be claimed. Police also need to be continuously vigilant on the negative impact of Neighborhood Watch.

\section{Conclusion}

Police are confronted with higher crime rates and fiscal constraints at the same time. Police-citizen coproduction citizen patrol, and neighborhood watch - are efforts to improve productivity and reduce crime and fear. There is a general belief that increased patrol and awareness can reduce crime and fear. Some actually report that these programs are making a difference. However, there is still much counter-evidence that citizen patrol and neighborhood watch programs do not make any difference. This may be because of the inherent limitation in watching activity, limited number of participants in a community to make a substantial difference, or lack of support and coordination effort from the police. Under what conditions, what percentage of participants of a given population can make a substantial difference has not been studied so far. The more people participate, the more likely they are to have stronger social cohesion and control. Thus, the police need to try to get more citizens involved in these activities, and not just let the numbers sit on the paper. And, the police also need to continue endorsing the programs to keep citizens from losing enthusiasm.

It is also important to retrain police officers and reorganize their structure to get the maximum output from these programs. Co-production calls for a new breed of police officer. Operationalizing a new professionalism based on democratic values such as participation and openness, rather than on technological values rooted in substantive expertise is an important consideration [25]. Thus, the police agencies need to train police officers to have more democratic values and change their attitudes.

There is a concern that these programs may increase inequity and have a reverse spillover effect, even if there is not enough actual evidence to support this argument. Therefore, the police should always carefully watch if these programs are causing any inequity between wealthy and poor neighborhood. And, if ever the police find out that they have adverse effect on poor neighborhoods in their district, they need to reallocate resources to compensate for the possible inequity and displacement impact caused by neighborhood watch program.

\section{References}

[1] National Commission on the Public Service, "Leadership for America: Rebuilding the Public Service," Washington D.C.: Paul A. Volcker, Chairman, 1989.

[2] J. Hawdon and J. Ryan, "Police-resident Interactions and Satisfaction with Police: An Empirical Test of Community Policing Assertions," Criminal Justice Policy Review, vol. 14, pp. 55-74, 2003.

[3] G. A. Gerasimos and J. G. Davis, "Reinventing or Repackaging Public Services? The Case of Community-Oriented Policing," Public Administration Review, vol. 58, pp. 485-498, 1998.

[4] A. Pattavina, J. M. Byrne and L. Garcia, "An Examination of Citizen Involvement in Crime Prevention in High-risk Versus Low- to Moderate-risk Neighborhoods," Crime and Delinquency, vol. 52, pp. 203-231, 2013.

[5] R. Warren, S. M. Rosentraub and S. K. Harlow, "Coproduction, Equity and the Distribution of Safety," Urban Affairs Quarterly, vol. 19, pp. 447-464, 1984.

[6] T. Bovaird, "Beyond Engagement and Participation: User and Community Coproduction of Public Services," Public Administration Review, vol. 67, pp. 846-860, 2007.

[7] T. Brannan, P. John and G. Stoker, "Active Citizenship and 
Effective Public Services and Programmes: How Can We Know What Really Works?," Urban Studies, vol. 43, pp. 993-1008, 2006.

[8] M. J. Marschall, "Citizen Participation and the Neighborhood Context: A New Look at the Coproduction of Local Public Goods," Political Research Quarterly, vol. 57, pp. 231-244, 2004.

[9] V. Pestoff, T. Brandsen and B. Verschuere, "New Public Governance, the Third Sector, and Co-production," New York, NY: Rutledge, 2012.

[10] L. S. Percy, "Citizen Involvement in the Co-producing Safety and Security in the Community," Public Productivity and Management Review, vol. 42, pp. 83-93, 1987.

[11] P. J. Lavarakas, J. Normoyle, W. G. Skogan, E. J. Hertz, G. Salem and D. A. Lewis, "Factors Related to Citizen Involvement in Personal, Household, and Neighborhood Anti-crime Measures," Washington, DC; Government Printing Office, 1981.

[12] P. D. Rosenbaum, "The Theory and Research behind Neighborhood Watch," Crime and Delinquency, vol. 33, pp. 103-134, 1987.

[13] National Institute of Justice, "Citizen Crime Prevention Tactics," U.S Department of Justice, 1980.

[14] M. Jakobsen, "Can Government Initiatives Increase Citizen Coproduction? Results of a Randomized Field Experiment," The Journal of Public Administration Research and Theory, vol. 23 , pp. 27-54, 2013

[15] National Institute of Justice, "Factors Influencing Crime and Instability in Urban Housing Developments," U.S. Department of Justice, 2007.
[16] E. Leher, "Communities and Cops Join Forces: Effectiveness of Community Policing," Insight on the News, vol. 15, pp. 16-25, 1999.

[17] E. Ostrom, "Crossing the Great Divide: Coproduction, Synergy, and Development," World Development, vol. 24, pp. $1073 \square 1087,1996$.

[18] National Institute of Justice, "Informal Citizen Action and Crime Prevention at the Neighborhood Level," U.S. Department of Justice, 1985.

[19] J. A. Schafer, B. Huebner and T. Bynum, "Citizen Perceptions of Police Services," Police Quarterly, vol. 6, pp. 440-468, 2003.

[20] L. William, "Equity and the Planning of Local Services," Journal of American Planning Association, vol. 47, pp. 447-457, 1981

[21] L. R. Lineberry, "Mandating Urban Equality; The Distribution of Municipal Public Services," N.Y: Longman, 1985.

[22] M. W. Rohe and S. W. Greenberg, "Participation in the Community Watch Programs," Journal of Urban Affairs, vol. 6, vol. 53-65, 1984.

[23] National Institute of Justice, "Safe and Secure Neighborhoods," U.S. Department of Justice, 1982.

[24] D. G. Suttles, "The Social Order of the Slum: Ethnicity and Territory in the Inner City," Chicago; University of Chicago Press, 1968.

[25] M. C. Scheider, T. Rowell and V. Bezdikian, "The Impact of Citizen Perceptions of Community Policing on Fear of Crime: Findings from Twelve Cities," Police Quarterly, vol. 6, pp. 363-386, 2003. 